\title{
PRINSIP KESANTUNAN DALAM LIRIK LAGU IWAN FALS
}

\section{Mijil Setyasih, Haryadi}

Jurusan Bahasa dan Sastra Indonesia, Fakultas Bahasa dan Seni, Universitas Negeri Semarang, Indonesia

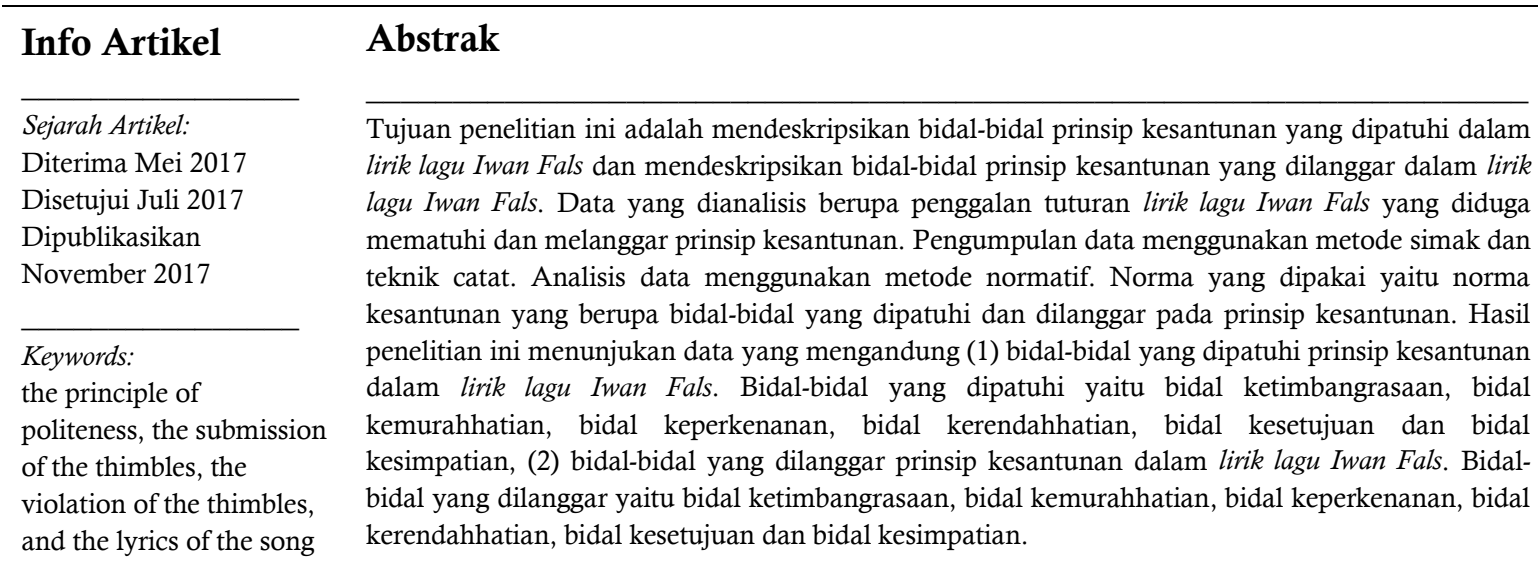

\section{Abstract}

The purpose of this study is to describe the thimbles of the principles of politeness are obeyed in the lyrics of the song Iwan Fals and describe the thimbles of the principles of politeness are violated in the lyrics of the song Iwan Fals. The data were analyzed in the form of lyrical fragments of Iwan Fals lyrics that allegedly obey and violate the principle of politeness. Data collection using the method refer and note technique. Data analysis using normative method. Norms used are the norm of politeness in the form of thimbles are obeyed and violated on the principle of politeness. The results of this study show data containing (1) thimbles that adhered to the principle of politeness in the lyrics of the song Iwan Fals. The heavily adhered thimbles are the thimble of the opposite, the thrill of mercy, the petal thimble, the humble thimble, the thimble of approval and the thimbles of the conclusion, (2) the thimbles that violated the principle of politeness in the lyrics of Iwan Fals. Broken thimbles of the opposite thimbles, the thrill of mercy, the favors of tolerance, the humble thimbles, the thimbles of approval and the thimbles of the conclusion.

\footnotetext{
Alamat korespondensi:

Gedung B1 Lantai 1 FBS Unnes

Kampus Sekaran, Gunungpati, Semarang, 50229

E-mail: mijilsetyasih20@gmail.com
} 


\section{PENDAHULUAN}

Penelitian tentang prinsip kesantunan dalam lirik lagu Iwan Fals menjadi problematika yang menarik untuk dikaji. Seringnya Iwan Fals menuturkan tuturan yang kurang santun dalam lirik-lirik lagunya dan kurang baik untuk di dengar oleh mitra tutur, baik sengaja maupun tidak. Tetapi di samping itu dalam lirik lagu Iwan Fals terdapat juga pematuhan prinsip kesantunan. Hal ini menjadi alasan diadakannya penelitian tentang prinsip kesantunan dalam lirik lagu Iwan Fals. Dengan adanya penelitian ini, diharapkan dapat diperoleh gambaran mengenai penggunaan bahasa dalam lirik lagu Iwan Fals. Masalah penelitian ini adalah (1) bidal-bidal prinsip kesantunan yang dipatuhi dalam lirik lagu Iwan Fals, dan (2) bidal-bidal prinsip kesantunan yang dilanggar dalam lirik lagu Iwan Fals. Dan tujuan dari penelitian ini adalah (1) mendeskripsikan bidal-bidal prinsip kesantunan yang dipatuhi dalam lirik lagu Iwan Fals, dan (2) mendeskripsikan bidal-bidal prinsip kesantunan yang Siangar dalam lirik lagu Iwan Fals.

Para peneliti bahasa yang telah melakukan penelitian ini, antara lain (1) Handayani (2003) meneliti tentang bidal-bidal prinsip kesantunan yang dilanggar , (2) Aristyani (2004) ditemukan pematuhan bidal-bidal prinsip kesantunan, (3) Latifah (2004) meneliti tentang pelanggaran dalam prinsip kesantunan, (5) Wahyuni (2006) meneliti tentang pelanggaran prinsip kesantunan, (6) Nafrati (2009) meneliti tentang pematuhan dan pelanggaran prinsip kesantunan, (7) Hidayah (2009) meneliti tentang pelanggaran prinsip kesantunan , (8) Deni (2010) meneliti tentang pematuhan dan pelanggaran prinsip kesantunan, (9) Jose (2012) meneliti tentang kesantunan dalam berbahasa, (10) Mahmoud (2012) meneliti tentang prinsipprinsip kesantunan, (11) Mahdi dan Seyyed (2015) meneliti tentang kesantunan.

Prinsip kesantunan Leech (dalam Rustono 1999:70) berisi bidal-bidal atau pepatah yang memberi nasehat yang harus dipatuhi agar tuturan penutur mematuhi prinsip kesantunan. Secara lengkap Leech mengemukakan prinsip kesantunan yang meliputi enam bidal beserta subbidalnya meliputi (1) subbidal bidal ketimbangrasaan yang terbagi menjadi dua yaitu minimalkan biaya kepada pihak lain dan maksimalkan keuntungan kepada pihak lain, (2) bidal kemurahhatian terbagi dua subbidal yaitu minimalkan keuntungan kepada diri sendiri dan maksimalkan keuntungan kepada pihak lain, (3) bidal keperkenanan terbagi dua subbidal yaitu minimalkan penjelekan kepada pihak lain dan maksimalkan pujian kepada pihak lain, (4) bidal kerendahhatian terbagi dua subbidal yaitu minimalkan pujian kepada diri sendiri dan maksimalkan penejelekan kepada diri sendiri, (5) bidal kesetujuan terbagi menjadi dua subbidal yaitu minimalkan ketidaksetujuan antara diri sendiri dan pihak lain dan maksimalkan kesetujuan antara diri sendiri dan pihak lain, dan (6) bidal kesimpatian terbagi dua subbidal yaitu minimalkan terbagi antipati antara diri sendiri dan pihak lain dan maksimalkan simpati antara diri sendiri dan pihak lain.

\section{METODE PENELITIAN}

Pendekatan yang digunakan dalam penelitian ini meliputi dua pendekatan, yaitu pendekatan teoretis dan metodologis. Secara teoretis, pendekatan yang digunakan dalam penelitian ini adalah pendekatan pragmatik. Pendekatan secara metodologis yang digunakan dalam penelitian ini adalah pendekatan kualitatif dan pendekatan deskriptif. Data penelitian ini adalah berupa tuturan-tuturan dalam penggalan lirik lagu Iwan Fals yang diduga mematuhi dan melanggar prinsip kesantunan. Metode yang digunakan untuk mengumpulkan data adalah metode simak dan teknik catat. Metode analisis data yang digunakan dalam penelitian ini adalah metode normatif, norma yang dipakai dalam penelitian ini, yaitu norma kesantunan yang berupa bidalbidal yang dipatuhi dan dilanggar pada prinsip kesantunan. Dalam penelitian ini teknik yang digunakan dalam penyajian hasil analisis adalah teknik penyajian secara informal.

\section{HASIL PENELITIAN DAN PEMBAHASAN}

Hasil penelitian ini meliputi dua hal yang sesuai dengan tujuan dan masalah yang diteliti, yaitu (1) Bidal-bidal prinsip kesantunan 
yang dipatuhi dalam lirik lagu Iwan Fals, (2) Bidal-bidal prinsip kesantunan yang dilanggar dalam lirik lagu Iwan Fals.

\section{Bidal-bidal Prinsip Kesantunan yang Dipatuhi dalam Lirik Lagu Iwan Fals}

Adapun bidal-bidal prinsip kesantunan yang dipatuhi di dalam penggalan-penggalan lirik lagu Iwan Fals meliputi (1) bidal ketimbangrasaan, (2) bidal kemurahhatian, (3) bidal keperkenanan, (4) bidal kerendahhatian, (5) bidal kesetujuan, (6) bidal kesimpatian.

\section{Pematuhan Bidal Ketimbangrasaan}

$\begin{array}{ll}\text { (1) KONTEKS } & \text { IWAN FALS } \\ & \text { MENUNJUKKAN } \\ & \text { RASA CINTA DAN } \\ \text { RELA } & \text { BERKORBAN } \\ & \text { DEMI } \\ & \text { KEMERDEKAAN } \\ & \text { DAN KEMAJUAN } \\ & \text { NEGERINYA } \\ & \text { YAITU BANGSA } \\ & \text { INDONESIA } \\ & \text { :"Apapun yang kan } \\ \text { Tuturan } & \text { terjadi } \\ & \begin{array}{l}\text { Aku tak kan lari } \\ \text { Apalagi } \\ \text { bersembunyi." }\end{array}\end{array}$

(data 26)

Tuturan yang diujarkan Iwan Fals pada lirik lagu di atas itu mematuhi prinsip kesantunan bidal ketimbangrasaan. Hal itu dapat dilihat dari tuturan "apapun yang kan terjadi aku tak kan lari, apalagi bersembunyi". Penutur tersebut berusaha akan selalu menghadapi apa pun yang akan terjadi atau yang akan menimpa di dalam bangsa Indonesia ini, penutur rela berkorban demi bangsanya agar tetap merdeka dan maju.

Dari uraian di atas dapat disimpulkan bahwa penutur dalam konteks ini yaitu Iwan Fals berupaya memberikan keuntungan yang sebesar-besarnya kepada mitra tutur yaitu bangsa Indonesia. Hal ini sesuai dengan bunyi bidal ketimbangrasaan yaitu minimalkan beban biaya kepada pihak lain dan maksimalkan keuntungan kepada pihak lain, sehingga tuturan tersebut mematuhi prinsip kesantunan bidal ketimbangrasaan

\section{Pematuhan Bidal Kemurahhatian}

$\begin{array}{lll}\text { (2) KONTEKS } & : \text { IWAN FALS } \\ & \text { MENCERITAKAN } \\ & \text { HARAPAN RAKYAT } \\ & \text { KEPADA } \\ & \text { PEMIMPIN YANG } \\ & \text { BARU BANGSA } \\ & \text { INDONESIA } & \\ \text { Tuturan } & : \text { "Biar kami cari } \\ & \text { sendiri." } & \\ & \text { (data 25) }\end{array}$

Tuturan yang diujarkan Iwan Fals termasuk tuturan yang mematuhi prinsip kesantunan bidal kemurahhatian. Hal ini dapat dilihat pada tuturan "Biar kami cari sendiri". Tuturan tersebut menunjukkan bahwa penutur yaitu Iwan Fals bersedia mencari sendiri untuk masalah moral dan masalah akhlak sehingga mitra tutur tidak susah payah untuk mencarinya, yang terpenting penutur hanya butuh mitra tutur yaitu Presiden untuk menegakkan peraturan yang sehat dan tegakkan hokum yang seadil-adilnya.

Dapat disimpulkan dari uraian di atas tuturan yang diujarkan Iwan Fals itu mengupayakan keuntungan yang sebesarbesarnya kepada mitra tuturnya yaitu Presiden, sedangkan diri sendiri atau penutur berupaya mendapatkan keuntungan yang sekecil-kecilnya. Oleh karena itu, tuturan tersebut dapat dikatakan mematuhi prinsip kesantunan bidal kemurahhatian.

\section{Pematuhan Bidal Keperkenanan}

$\begin{array}{ll}\text { (3) KONTEKS } & \text { :IWAN FALS } \\ & \text { MENGGAMBARKA } \\ & \text { N SEORANG GADIS } \\ & \text { YANG DISUKAI } \\ & \text { DIKELASNYA } \\ \text { :"Dia adalah gadis } \\ \text { juturan } & \text { jelita } \\ & \text { Tak pernah banyak } \\ & \text { tingkah } \\ & \text { Didalam kelas dialah } \\ & \text { ratu } \\ & \text { Tak ada } \\ & \text { bandingannya." } \\ \text { (data 10 ) }\end{array}$

Tuturan yang diujarkan oleh Iwan Fals sebagai penutur mematuhi bidal keperkenanan karena 
penutur meminimalkan penjelekan pada mitra tutur dan memaksimalkan pujian pada mitra tutur. Terlihat jelas dari tuturan dia adalah gadis jelita, didalam kelas dialah ratu, penutur sangat memuji mitra tutur yaitu gadis yang disukainya. Penutur disini mempunyai rasa suka terhadap mitra tutur dan dia selalu memujinya, penutur mengatakan bahwa mitra tutur adalah gadis yang cantik jelita, dia merasa bahwa gadis tersebut gadis yang tidak ada bandingannya dengan gadis-gadis lain dikelasnya dan dia hanya cinta kepadanya. Penutur juga mengatakan gadis itu tidak banyak tingkah dikelas,

Jadi dari uraian di atas dapat disimpulkan tuturan tersebut mematuhi prinsip kesantunan pada bidal keperkenanan karena penutur disini lebih memaksimalkan pujian kepada mitra tutur.

\section{Pematuhan Bidal Kerendahhatian}

$\begin{array}{ll}\text { (4) KONTEKS } & \text { :IWAN FALS } \\ & \text { BERCERITA } \\ & \text { DIRINYA } \\ & \text { MENINGGALKAN } \\ & \text { RUMAH DENGAN } \\ & \text { TERPAKSA DAN } \\ & \text { MERASAKAN } \\ & \text { RINDU } \text { TEBAL KEPADA } \\ & \text { KELUARGA } \\ & \text { RUMAH } \\ & \text { :"Aku pergi } \\ \text { meninggalkan coreng } \\ \text { Tuturan } \\ \text { hitam dimuka bapak } \\ \text { Yang membuat malu } \\ \text { keluargaku } \\ \text { Ku ingin kembali } \\ \text { mungkinkah mereka } \\ \text { mau terima rinduku } \\ \text { (data 15) }\end{array}$

Tuturan yang diujarkan Iwan Fals di atas merupakan tuturan yang mematuhi prinsip kesantunan bidal kerendahhatian karena penutur memaksimalkan penjelekan pada dirinya sendiri. Disini sebenarnya penutur merasakan rindu yang amat dalam kepada keluarga di tanah kelahirannya, tetapi penutur berfikiran bahwa rasa rindu dirinya tidak lagi diterima oleh keluarganya. Penutur merasa telah mencoreng nama baik Ayahnya dan juga sudah membuat malu keluarganya dirumah, sehingga penutur menyesali perbuatannya dan meminta maaf atas semua kesalahannya.

Jadi dari uraian di atas dapat disimpulkan tuturan tersebut termasuk tuturan yang mematuhi prinsip kesantunan bidal kerendahhatian karena penutur lebih memaksimalkan penjelekan kepada dirinya sendiri.

\section{Pematuhan Bidal Kesetujuan}

\section{(5) KONTEKS}

\begin{tabular}{|c|c|}
\hline \\
\hline BERUSAHA & \\
\hline MEMBUJUK & \\
\hline KEKASIHNYA & \\
\hline SUPAYA & \\
\hline PERCAYA & \\
\hline KEPADA & \\
\hline T & \\
\hline
\end{tabular}

Tuturan

:"Bila itu maumu, tak mungkin kuhalangi." (data 13)

Tuturan yang diujarkan Iwan Fals yang berbunyi Bila itu maumu, tak mungkin kuhalangi merupakan tuturan yang mematuhi prinsip kesantunan bidal kesetujuan, karena penutur Iwan Fals lebih memaksimalkan kesetujuannya antara diri sendiri dan pihak lain dalam hal ini kekasihnya. Disini penutur merasa setuju dengan apa yang disampaikan oleh mitra tutur yaitu kekasihnya, mitra tutur mengatakan agar penutur pergi dari kehidupannya dan menyuruhnya untuk melupakannya. Mitra tutur merasa tidak mudah untuk begitu saja percaya lagi kepada penutur, dan disini penutur menjawab bahwa dirinya bisa menerima apa yang disampaikan oleh mitra tutur dan tidak bisa menghalangi apa yang di inginkannya yaitu dirinya di suruh untuk pergi dan melupakan dari kehidupan kekasihnya itu.

\section{Pematuhan Bidal Kesimpatian}

$\begin{array}{ll}\text { (6) KONTEKS } & \text { :IWAN FALS } \\ & \text { MEMBERIKAN } \\ & \text { RASA CINTA, } \\ & \text { SIMPATI DAN } \\ & \text { BERTERIMA } \\ & \text { KASIH KEPADA }\end{array}$




$\begin{aligned} & \text { SEORANG } \\ & \text { PELACUR YANG } \\ & \text { TELAH } \\ & \text { MENOLONGNYA } \\ & \text { Tuturan : } \text { "Benih cinta tak } \\ & \text { pandang siapa } \\ & \text { Meski semua orang } \\ & \text { singkirkan kita } \\ & \text { Genggam tangan } \\ & \text { erat-erat kita } \\ & \text { melangkah." } \\ & \text { (data 8) }\end{aligned}$

Dalam tuturan tersebut sudah jelas bahwa penutur yaitu Iwan Fals memperlihatkan rasa simpatinya kepada mitra tuturnya yaitu seorang pelacur atau lonte. Memperlihatkan rasa simpatinya dengan cara memberikan semangat kepada seorang pelacur itu, penutur mengatakan walaupun mitra tutur bekerja dalam dunia gelap sebagai wanita penghibur (pelacur),tetapi harus tetap di jalani dan harus tetap melangkah dengan semangat walaupun semua orang menyingkirkan atau menghina mitra tutur karena pekerjaannya sebagai seorang pelacur itu.

Dari uraian di atas dapat di simpulkan tuturan tersebut mematuhi prinsip kesantunan pada bidal kesimpatian karena penutur masih tetap mempunyai rasa peduli dan simpati kepada mitra tuturnya walaupun pekerjaan mitra tutur tersebut seorang pelacur atau wanita penghibur.

\section{Bidal-bidal Prinsip Kesantunan yang Dilanggar dalam Lirik Lagu Iwan Fals}

Bidal-bidal prinsip kesantunan yang dilanggar di dalam penggalan-penggalan lirik lagu Iwan Fals meliputi (1) bidal ketimbangrasaan, (2) bidal kemurahhatian, (3) bidal keperkenanan, (4) bidal kerendahhatian, (5) bidal kesetujuan, (6) bidal kesimpatian.

\section{Pelanggaran Bidal Ketimbangrasaan}

(7) KONTEKS

:IWAN FALS
BERHARAP
WAKIL
RAKYATNYA
MENYAMPAIKAN

\section{SEMUA ASPIRASI \\ RAKYAT KEPADA \\ PRESIDEN \\ REPUBLIK \\ INDONESIA}

\section{Tuturan :"Suara kami tolong dengar lalu sampaikan!}

(data 21)

Tuturan yang diujarkan Iwan Fals merupakan tuturan yang melanggar bidal ketimbangrasaan karena penutur tidak meminimalkan biaya kepada pihak lain dan tidak memaksimalkan keuntungan kepada pihak lain. Terlihat jelas dalam tuturan yang berbunyi suara kami tolong dengar lalu sampaikan! tuturan tersebut kurang santun dan bertujuan memerintah mitra tuturnya yaitu wakil rakyat atau anggota DPR untuk mendengar suara para rakyatnya dan juga menyampaikan semua aspirasi masyarakat terhadap presiden Republik Indonesia.

Hal ini berarti penutur membebankan biaya kepada mitra tuturnya yaitu anggota DPR, hal ini sangat bertentangan dengan bunyi bidal prinsip kesantunan subbidal pertama yang menekankan bahwa penutur hendaknya meminimalkan biaya pada lawan tutur dalam konteks ini yaitu anggota DPR.

\section{Pelanggaran Bidal Kemurahhatian}

$\begin{array}{ll}\text { (8) KONTEKS } & \text { :IWAN FALS } \\ & \text { MENGKRITIK } \\ & \text { PEMIMPIN BARU } \\ & \text { BANGSA } \\ & \text { INDONESIA }\end{array}$

$\begin{array}{lll}\text { Tuturan } & \text { :"Kamu harus } & \text { dengar } \\ & \text { suara ini } & \\ & \begin{array}{l}\text { Turunkan } \\ \text { secepatnya }\end{array} & \text { harga } \\ & \\ & \text { Berikan } \\ \text { pekerjaan." } & \text { kami }\end{array}$

(data 24)

Penutur disini bertujuan untuk memerintah kepada mitra tutur yaitu Presiden, terlihat dari tuturannya penutur memerintah mitra tutur untuk mendengarkan semua suara-suara rakyat yang mulai merasakan kebosanan hidup di negerinya. Penutur juga memerintah kepada 
mitra tutur agar menurunkan semua harga-harga di dalam bangsa Indonesia yang kini mulai naik harga-harganya menjadi mahal karena masih banyak rakyat-rakyat kecil yang kesusahan untuk membeli kebutuhan hidupnya, penutur juga meminta kepada mitra tutur agar pengangguran di negeri ini segera diberikan pekerjaan.

Dapat disimpulkan dari uraian di atas bahwa tuturan tersebut kurang santun dan melanggar prinsip kesantunan bidal kemurahhatian, penutur terlihat banyak memberikan perintah kepada mitra tutur sehingga mitra tutur mendapat keuntungan yang sekecil-kecilnya dan penutur berusaha mendapatkan keuntungan yang sebesarbesarnya.

3. Pelanggaran Bidal Keperkenanan

(9) KONTEKS

:IWAN FALS

MENCERITAKAN

PARA PEJABAT

YANG SUKA

MELAKUKAN

KORUPSI DAN

SERING

MENGINGKARI

JANJINYA

Tuturan : "Yang suka berenang

disungai yang kotor

Kisah using tikustikus berdasi

Yang suka ingkar janji."

(data 16)

Sudah sangat terlihat penutur disini melakukan sindirian kepada para pejabat yang suka melakukan korupsi dan yang suka mengingkari akan janji-janjinya. Pejabat disini sebagai mitra tutur merasa sangat tersinggung atas sindiran yang diucapkan oleh penutur, penutur beranggapan mitra tutur telah memakan uang kotor yang bukan haknya dengan kata lain melakukan korupsi dikantornya, mitra tutur juga sering ingkar janji.

Jadi tuturan tersebut sangat menyindir dan membuat tersinggung mitra tuturnya, sehingga dari uarian diatas dapat disimpulkan tuturan tersebut termasuk tuturan yang melanggar prinsip kesantunan pada bidal keperkenanan karena terlihat dari penutur yang lebih memaksimalkan penjelekan kepada mitra tuturnya.

\section{Pelanggaran Bidal Kerendahhatian}

$\begin{array}{ll}\text { (10) KONTEKS } & \text { :IWAN FALS } \\ \text { MENGGAMBARK } \\ \text { AN DIRINYA } \\ \text { SEORANG } \\ \text { PENGUSAHA } \\ \text { PAPAN ATAS } \\ \text { YANG KAYA DAN } \\ \text { MEMPUNYAI } \\ \text { SEGALANYA }\end{array}$

Tuturan :"Mobilku banyak, harta melimpah

Wajahku ganteng, banyak simpanan."

(data 10)

Penutur menganggap bahwa dirinya mempunyai segalanya dari wajah yang tampan dan bisa mendapatkan segalanya dari uang yang dimilikinya. Penutur juga beranggapan dengan dirinya mempunyai banyak uang dengan mudah bisa mendapatkan dan memilih seorang wanita yang disukainya. Dia juga menganggap diirnya orang nomer satu sehingga orang-orang memanggilnya bos eksekutif.

Sehingga dapat disimpulkan dari uraian di atas bahwa penutur disini sangat terlihat sombong sehingga tuturan tersebut dapat dikatakan melanggar prinsip kesantunan pada bidal kerendahhatian.

\section{Pelanggaran Bidal Kesetujuan}

\begin{tabular}{|c|c|}
\hline (11) KONTEKS & :IWAN \\
\hline & MENCERITAKAN \\
\hline & SEMUA TRAGEDI \\
\hline & BENCANA ALAM \\
\hline & TERJADI \\
\hline & SEMUA \\
\hline & PERINGATAN \\
\hline & TUHAN \\
\hline & UNTUK \\
\hline & UMATNYA \\
\hline Tuturan & :"Ini bukan sandiwara \\
\hline & $\begin{array}{l}\text { Ini bukan dala } \\
\text { mimpi }\end{array}$ \\
\hline
\end{tabular}


Ini bukan sandiwara Ini bukan dalam mimpi."

data 38)

Di sini penutur yaitu Iwan Fals merasa tidak setuju dengan mitra tutur dalam hal ini warga Indonesia, mitra tutur beranggapan bahwa semua bencana alam yang terjadi itu bukan disebabkan dari tingkah laku manusia itu sendiri. Tetapi penutur mengatakan bahwa semua bencana-bencana alam yang menimpa bangsa kita itu semua terjadi karena dari tingkah manusia itu sendiri dan semua itu memang kenyataan bukan hanya dalam mimpi. Terlihat dari tuturan yang berbunyi ini bukan sandiwara , ini bukan dalam mimpi.

Dari uraian di atas dapat di simpulkan bahwa tuturan tersebut merupakan tuturan yang melanggar prinsip kesantunan dalam subbidal kesetujuan yaitu memaksimalkan ketidaksetujuan antara diri sendiri dan pihak lain, karena penutur di sini terlihat tidak menyetujui apa yang menjadi pendapat mitra tutur.

\section{Pelanggaran Bidal Kesimpatian}

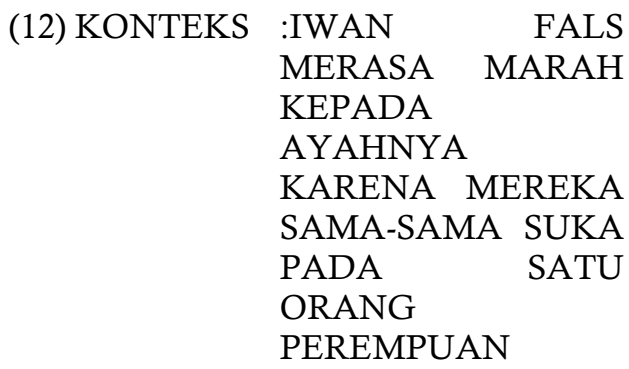

Tuturan $\quad$ "Dasar bapakku
Tak tahu malu."

(data 32)

Penutur merasa kesal dan marah kepada mitra tutur yaitu Ayahnya karena Ayahnya telah berbohong kepada penutur. Mitra tutur telah menyembunyikan sesuatu dari penutur yaitu mitra tutur diam-diam juga menyukai seorang perempuan yang di sukai oleh penutur. Jadi penutur merasa telah di bohongi oleh Ayahnya sendiri, dalam hal ini seharusnya penutur lebih menunjukkan simpati kepada Ayahnya dengan cara bicara baik-baik kepadanya karena yang telah dilakukan itu salah.

Dari uraian di atas dapat disimpulkan bahwa tuturan yang di ujdrkan Iwan Fals termasuk tuturan yang melanggar prinsip kesantunan dalam bidal kesampatian, karena seharusnya penutur memaksimalkan simpati antara diri sendiri dan pihak lain tetapi sebaliknya penutur lebih memaksimalkan antipati antara diri sendiri dan pihak lain dalam hal ini Ayahnya.

Dari pembahasan di atas dapat disimpulkan bahwa lirik lagu Iwan Fals sesuai dengan teori prinsip kesantunan Leech yaitu lirik lagu Iwan Fals banyak yang mematuhi prinsip kesantunan antara lain bidal ketimbangsaan, bidal kemurahhatian, bidal keperkenanan, bidal kerendahhatian, bidal kesetujuan, dan bidal kesimpatian. Lirik lagunya juga banyak yang melanggar prinsip kesantunan meliputi bidal ketimbangrasaan, bidal kemurahhatian, bidal keperkenanan, bidal kerendahhatian, bidal kesetujuan dan bidal kesimpatian.

\section{SIMPULAN}

Pematuhan prinsip kesantunan dalam lirik lagu Iwan Fals diperoleh 24 data meliputi 2 pematuhan bidal ketimbangrasaan, 2 pematuhan bidal kemurahhatian, 5 pematuhan bidal keperkenanan, 2 pematuhan bidal kerendahhatian, 3 pematuhan bidal kesetujuan, dan 10 pematuhan bidal kesimpatian. Lirik lagu yang melanggar prinsip kesantunan diperoleh 17 data ,meliputi: 2 bidal ketimbangrasaan, 2 bidal kemurahhatian, 7 bidal keperkenanan, 2 bidal kerendahhatian, 2 bidal kesetujuan, dan 2 bidal kesimpatian.

\section{DAFTAR PUSTAKA}

A Al-Khatib, Mahmoed. 2012. Politeness in The Holy Qur'an : A sosiolinguistis Ana Pragmatic Perspective. Interculture Pragmatic Vol 9 (4) 479-509.

Aristyani, Yulia. 2004. Kesantunan Dalam Dialog Wacana Dongeng Anak-Anak Berbahasa 
Indonesia. Skripsi. Universitas Negeri Semarang.

Handayani, Eni. 2003. Pelanggaran Prinsip Kesantunan dalam Wacana Ketoprak Humor di RCTI. Skripsi. Universitas Negeri Semarang.

Hidayah, Nur. 2009. Jenis Tindak Tutur dan Pelanggaran Prinsip Kesantunan dalam Wacana Empat Mata di Trans-7. Skripsi. Universitas Negeri Semarang.

Latifah, Firda. 2004. Pelanggaran Kesantunan Penjual dan Pembeli dalam Transaksi Jual Beli di Pasar Induk Banjarnegara. Skripsi. Universitas Negeri Semarang.

Mahdi dan Seyyed. 2015. Pragmatic Ana Politeness Strategies in Some Shi'a Supplications. Language Related Research Vol 5, No.5.

Maria Gil, Jose. 2012. "Face Threatening Speech Acts And Face-Invading Speech Acts: An Interpretation of Politeness Phenomena". International Journal of Linguistics. ISSN 1948-5425. Vol 4, No. 2.

Moeloeng, Lexy. J.2000. Metode Penelitian Kualitatif. Jakarta : PT. Remaja Rosdakarya.

Narulita, Diah Nafrati. 2009. Pematuhan dan Pelanggaran Prinsip Kesantunan dalam Interaksi Sosial Masyarakat Etnis Arab di Kota Pekalongan pada Ranah Ketetanggaaan. Skripsi. Universitas Negeri Semarang.

Rustono. 1999. Pokok-Pokok Pragmatik. Semarang : CV. IKIP Semarang Press.

Septyaningtyas, Deni. 2010. Kesantunan dalam Wacana Humor Bukan Abdel Temon Biasa di Global TV. Skripsi. Universitas Negeri Semarang.

Sudaryanto. 1993. Metode dan Aneka Teknik dan Bahasa; Pengantar Penelitian Wahana Kebudayaan Secara Linguistik. Yogyakarta : Duta Wacana University Press.
Wahyuni, Sri. 2004. Bahasa Plesetan Ala Extravaganza di Trans TV, Kajian Atas Pelanggaran Prinsip Kesantunan. Skripsi. Universitas Negeri Semarang. 